\title{
Çok Boyutlu Veri Görselleştirme Yöntemlerinden Chernoff Yüzleri Yöntemi Kullanılarak Üniversitelerin İstatistik Bölümlerinin Kpss Başarı Puanlarının Karşılaştırılması
}

\begin{abstract}
Selahattin YAVUZ*゚, Elanur KULAÇC
Erzincan Binali Yıldırım Üniversitesi, İktisadi ve İdari Bilimler Fakültesi, İşletme Bölümü, Erzincan 24000, Türkiye.

Sivas Cumhuriyet Üniversitesi, Sosyal Bilimler Enstitüsü, İșletme Anabilim Dalı Lisansüstü Öğrencisi, Sivas 58000, Türkiye.

Geliş / Received: 31/10/2019, Kabul / Accepted: 20/02/2020

\section{$\ddot{\mathbf{O} z}$}

Verilerin görselleştirme yöntemi olan grafik ve tablolar kullanılarak verilerin okuyucuya sunulması oldukça önemlidir. Okuyucu, metin içerisine gizlenmiş olan gizli ilişsileri grafik ve tablolar yardımıyla daha kolay anlayabilmektedir. Tek boyutlu ve çok boyutlu veri görselleştirme yöntemi bulunmaktadır. Bu çalışmada çok boyutlu veri görselleştirme yöntemlerinden Chernoff yüzleri yöntemi kullanılarak 20 devlet ve 2 özel olmak üzere 22 üniversitenin istatistik bölümlerinin KPSS başarı puanları bakımından karşılaştııılmıştır. Chernoff yüzleri grafiğini çizmek için SYSTAT programı kullanılmıştır. Çalışma sonucunda söz konusu alanda hangi üniversite veya üniversitelerin daha başarılı olduğu ve hangi üniversite veya üniversitelerin daha başarısız bulunduğu belirlenmiş̧ir.
\end{abstract}

Anahtar Kelimeler: Tablo ve Grafikler, Veri Görselleștirme, Chernoff Yüzleri, İstatistik Bölümü

\section{Comparison of Kpss Achievement Scores of University's Statistical Departments by Using Chernoff Faces Method, which is one of the Multidimensional Data Visualization Methods}

\begin{abstract}
It is very important to present the data to the reader by using graphics and tables, which are the visual methods of the data. The reader can more easily understand the hidden relationships in the text by means of graphics and tables. One-dimensional and multi-dimensional data visualization methods are available. In this study, using the Chernoff faces method, one of the multidimensional data visualization methods, 22 universities (20 public and 2 private universities), were compared in terms of their KPSS grades. SYSTAT program was used to plot the Chernoff faces. As a result of the study, it was determined which university or universities was/were more successful and unsuccessful.
\end{abstract}

Keywords: Tables and Graphics, Data Visualization, Faces of Chernoff, Department of Statistics

* Sorumlu Yazar:selahyavuz@hotmail.com 


\section{Giriş}

Verilerin, okuyucuların anlayacağı biçimde sunulması oldukça önemlidir. Günümüzde derinleşen yani birçok değişkeni birlikte içinde barındıran bilginin daha kolay ve doğru anlaşılması için kullanılacak olan görselleştirme yönteminin seçilmesi oldukça önemli hale gelmiştir. Verilerin kolay ve anlaş1lır bir biçimde sunulduğu yöntemlerden biri şüphesiz tablo ve grafik gibi görsel yöntemlerdir. Tablo ve grafikler, yapılan çalışmayı desteklemek amacıyla bazı gerçekleri veya ilişkileri kapsamlı ve açık biçimde göstermek için, rakamların, kelimelerin veya farklı türdeki unsurların belirli ve sıkıştırılmış yani özet biçimde düzenlenmesidir.

Tablolar ve grafikler insanlık tarihinde bilgi aktarımı için kullanılan ilk araçlar arasında ve bilimin gelişmesinde önemli role sahip olmuşlardır. Bilim dünyasında yüz yıllardan beri istatistik verilerin aktarılması için tablolar ve grafikler kullanılmaktadır (Bezerra, vd.,1998; Yıldız ve Yildırım, 2012).

İnsanın algılama sistemi yalnızca 3 boyut ile sınırlı olduğu için daha fazla boyut içeren veriler insanın algılama sınırını aşmaktadır. Veri görselleştirme teknikleri çok boyutlu veriyi 2 veya 3 boyuta indirgeyerek görselleştirirken, diğer taraftan da veriler arasındaki ilişkiyi muhafaza edebilmektedir. $\mathrm{Bu}$ indirgeme sirasında bir miktar kayıp olması kaçınılmazdır. Görselleştirmede temel hedeflerden biri bu kaybı minimum düzeyde tutmaktır. Veri görselleştirmenin iki temel amacı bulunmaktadır. Birinci amaç; fikirlerin, kuralların ve kavramların daha iyi anlaşılmasıdır. Tüm bunlar bir bilgi olduğu için bu tür görselleştirmelere "bilgi görselleştirmesi” (knowledge visualization) denir. Diğer amaç ise grafiklerin ve resimlerin yeni fikirler oluşturmak, yeni ilişkiler kurmak, bir hipotezin doğruluğunu sınamak, yeni yapilar keşfetmek veya bu yapıları düzenlemektir. Özetle, bu işlemler insanın görsel algılama sistemini mantıksal problemlerin ç̧̈zümü için kullanmaktır (Bilgin ve Çamurcu, 2008).

Tek boyutlu ve çok boyutlu birçok veri görselleştirme yöntemi bulunmaktadır. Bu çalışmada çok boyutlu veri görselleştirme yöntemlerinden Chernoff yüzleri yöntemi kullanılarak üniversiteler (20 devlet ve 2 özel üniversite), istatistik bölümlerinin mezun öğrencilerin farklı alanlarda (İstatistik, Ekonometri, Genel Kültür, Genel Yetenek, İktisat, İşletme, Kamu Yönetimi, Maliye, Muhasebe, Çalışma Ekonomisi, Hukuk) almış oldukları kpss başarı puanlarına göre karşılaş̧ırılmışıı. Üniversitelere göre ders müfredatları farkl11ık gösterdiğinden dolayı söz konusu derslerin bir kısmı bazı üniversitelerde seçmeli iken bazı üniversitelerde zorunlu ve bazı üniversitelerde ise olmayabilmektedir. Fakat istatistik bölümü mezunları atanmak istedikleri kadrolar için gerekli olan dersten soru cevaplamaları gerekmektedir. Dolayısıyla söz konusu dersler seçilirken bu durum dikkate alınmıştır.

\section{Materyal}

Çalışmanın materyalini 20 devlet ve 2 özel olmak üzere 22 üniversitenin istatistik bölümü mezunlarının KPSS sınavına katılıp İstatistik, Ekonometri, Genel Kültür, Genel Yetenek, İktisat, İşletme, Kamu Yönetimi, Maliye, Muhasebe, Çalışma Ekonomisi ve Hukuk olmak üzere 11 farklı alanda almış oldukları ortalama başarı puanları oluşturmaktadır. Başarı puanları için ÖSYM tarafından en son yayınlanan 5 yılın başarı ortalamaları dikkate alınmıştır. Üniversiteler 
ve ilgili alanlarda alınan başarı ortalamaları

Tablo 1'de verilmiştir.

Tablo 1. Üniversiteler ve alanlara göre başarı puanları

\begin{tabular}{|c|c|c|c|c|c|c|c|c|c|c|c|}
\hline Üniversiteler & 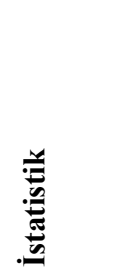 & 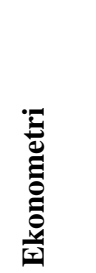 & 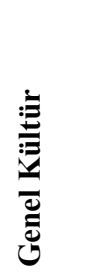 & 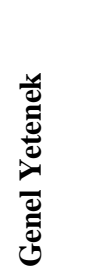 & 莺 & 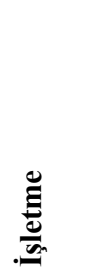 & 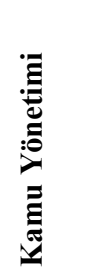 & 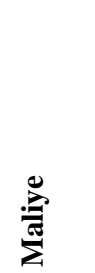 & 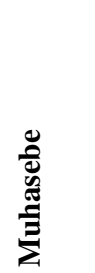 & 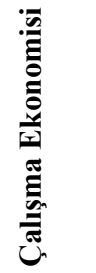 & $\begin{array}{l}\text { 兰 } \\
\text { 总 }\end{array}$ \\
\hline Orta Doğu Teknik Üniv. & 13,222 & 4,974 & 22,168 & 43,458 & 6,074 & 7,300 & 3,112 & 3,202 & 3,048 & 1,434 & 4,364 \\
\hline Hacettepe Üniv. & 11,680 & 2,766 & 20,104 & 38,762 & 4,984 & 6,244 & 2,768 & 3,192 & 3,042 & 2,512 & 4,084 \\
\hline Gazi Üniv. & 9,978 & 2,178 & 19,398 & 34,994 & 4,092 & 5,534 & 2,962 & 3,162 & 2,932 & 2,654 & 4,086 \\
\hline Ankara Üniv. & 9,768 & 2,358 & 19,622 & 36,174 & 4,388 & 5,280 & 3,012 & 3,416 & 3,046 & 2,178 & 4,514 \\
\hline Dokuz Eylül Üniv. & 7,476 & 2,836 & 12,942 & 34,584 & 4,654 & 5,996 & 3,056 & 3,742 & 3,774 & 2,950 & 4,476 \\
\hline Anadolu Üniv. & 6,242 & 3,386 & 18,422 & 33,400 & 4,138 & 5,824 & 3,334 & 3,396 & 3,056 & 3,256 & 4,354 \\
\hline Ege Üniv. & 6,654 & 2,630 & 17,662 & 34,920 & 4,356 & 6,188 & 3,302 & 3,168 & 3,850 & 3,172 & 4,404 \\
\hline Yıldız Teknik Üniv. & 5,680 & 3,868 & 16,712 & 36,668 & 4,726 & 6,232 & 3,456 & 4,034 & 3,646 & 3,162 & 4,450 \\
\hline Eskişehir Osmangazi Üniv. & 5,678 & 1,968 & 16,908 & 31,232 & 3,744 & 5,796 & 3,094 & 2,930 & 2,628 & 3,268 & 4,162 \\
\hline Ufuk Üniversitesi & 5,124 & 1,656 & 16,876 & 28,398 & 2,987 & 6,760 & 3,290 & 4,007 & 2,630 & 3,630 & 4,777 \\
\hline Mimar Sinan Güzel Üniv. & 5,494 & 3,400 & 17,868 & 35,152 & 4,850 & 6,444 & 3,606 & 2,698 & 3,650 & 4,204 & 4,900 \\
\hline Sinop Üniv. & 6,128 & 1,958 & 13,234 & 25,712 & 2,397 & 3,727 & 2,230 & 2,177 & 0,350 & 2,526 & 1,760 \\
\hline Marmara Üniv. & 4,390 & 1,563 & 14,753 & 32,363 & 4,127 & 4,227 & 2,507 & 2,943 & 3,173 & 3,663 & 3,013 \\
\hline Çukurova Üniv. & 5,184 & 1,912 & 17,378 & 31,636 & 4,278 & 4,772 & 3,470 & 3,280 & 2,672 & 3,250 & 4,748 \\
\hline Giresun Üniv. & 4,192 & 1,836 & 13,382 & 26,304 & 1,953 & 3,600 & 2,480 & 2,627 & 1,097 & 2,782 & 1,185 \\
\hline Muğla S.Koçman Üniv. & 5,204 & 2,182 & 15,886 & 30,702 & 4,040 & 4,508 & 3,010 & 3,488 & 3,180 & 2,678 & 4,330 \\
\hline Selçuk Üniv. & 4,946 & 1,176 & 16,156 & 28,740 & 3,120 & 4,616 & 2,328 & 2,592 & 2,306 & 2,866 & 4,074 \\
\hline Kırıkkale Üniv. & 5,710 & 1,896 & 16,278 & 29,556 & 3,134 & 4,152 & 2,946 & 2,886 & 2,746 & 2,752 & 4,118 \\
\hline Afyon Kocatepe Üniv. & 4,530 & 2,124 & 14,824 & 28,862 & 2,858 & 4,556 & 2,652 & 1,992 & 1,932 & 3,048 & 3,572 \\
\hline OndokuzMayıs Üniv. & 4,958 & 1,434 & 17,598 & 29,416 & 3,436 & 4,514 & 3,554 & 2,986 & 2,910 & 3,370 & $\overline{4,046}$ \\
\hline Frrat Üniv. & 3,194 & 0,674 & 15,572 & 26,108 & 2,392 & 4,168 & 2,604 & 2,058 & 1,288 & 2,930 & 3,916 \\
\hline Yaşar Üniv. & 4,434 & 1,534 & 15,614 & 30,452 & 3,170 & 6,020 & 2,884 & 2,193 & 2,330 & 3,233 & 3,870 \\
\hline
\end{tabular}

\section{Yöntem}

Bu başlık altında veri görselleştirme yöntemi ve veri görselleştirme yöntemlerinden Chernoff'un yüzleri yöntemi üzerinde durulacaktır.

\subsection{Veri Görselleştirme Yöntemi}

Veri görselleştirme, ham verilerin hızlı ve etkili karar almada kolayca anlaşılır görüntülere yani fotoğraflara dönüştürülme sürecidir (www.verigazeteciligi.com > verigorsellestirme-nedir).

Veriler tablo ve grafikler yardımıyla görsel hale getirilerek verilerin ve değişkenlerin daha doğru anlaşılması kolaylaşır. Tablo ve grafiklerin kullanımı gelişen bilgi teknolojileriyle birlikte artmış ve standart hale gelmiştir. Grafik ve tablo kullanımının 
sağladığı faydaları şöyle sıralayabiliriz (Fienberg, 1975; Wainer, 1992; Y1ldı ve Y1ldırım, 2012):

$\checkmark$ Grafikler ve tablolar yazıya göre okuyucunun ilgisini daha fazla çeker,

İyi hazırlanmış grafik ve tablolar soyut gerçekleri somut (görünür) hale getirdiğinden daha kolay anlaşılır ve hatırlanması daha kolaydır,

$\checkmark$ Grafik ve tablo kullanımıyla verilerin görünür hale gelmesi, anlama süresini kısaltarak, zaman tasarrufu sağlar,

$\checkmark$ Grafik ve tablolar ele alınan konudaki problemleri bir bütün olarak sergiler. Böylece bütünlüğü bozulmayan bağlam içinde, problemler daha doğru tespit edilir,

$\checkmark$ Grafik ve tablolar istatistik veriler arasındaki gizli ilişkileri fark etmeyi sağlar. Bundan dolayı grafik ve tablolar birer keşif aracıdır,

$\checkmark$ Grafik ve tablolar binlerce kelimeyle anlatılamayacak bilgilerin kolayca sunulmasını sağlar.

Tablo ve grafikler araştırma sonucunda elde edilen verilerin sayısal olarak anlaşılabilir bir şekilde sunulmasını sağlayan araçlardır. Değişkenler arasındaki ilişkilerin görsel olarak da anlaşılmasına hizmet ederler. Verilerin analizini ve yorumlanmasinı kolaylaştırırlar. Karmaşık sonuçların "okunabilir" biçimde sunulmasına yardım ederler (www.halksagligi.hacettepe.edu.tr , sunumlar_ve_seminerler > epidemiyoloji).

Veri görselleştirme, soyut bilgilerin analiz sonuçlarının grafikler, diyagramlar, tablolar, resimler veya animasyonlar oluşturarak sunulmasıdır. Görselleştirmede amaç, istatistiksel ve değişken bilgilerinin klasik formatta sunulan kompleks verileri, kolay algilanabilecek grafik arayüzler ile rahat anlaşılır hale getirmektir. İnsan algılama sistemi 3 boyut ile kisitlanmakta ve daha yüksek boyutlu veri yapıları, insanın algılama sınırlarının dışına çıkmaktadır. Görselleştirme sayesinde çok boyutlu veriler boyut indirgemesi yapilarak 2 ya da 3 boyuta indirgenerek daha anlaşı1ır hale getirilir (Bilgin vd., 2008). Yapılan araştırmalar insanların görsellere diğer herhangi bir uyarandan daha iyi tepki verdiğini göstermektedir. İnsan beyni görsel bilgiyi metinden 60.000 kat daha hızlı işler (Çelik ve Akdamar, 2018).

Çok boyutlu veri görselleştirme araçları, birçok çalışmaları ile tanınan Kriegel ve Keim tarafından altı temel sınıfa ayrılmıştır. Bunlar, geometrik izdüşüm teknikleri, ikon tabanlı teknikler, piksel tabanlı teknikler, hiyerarşik teknikler, graf tabanlı teknikler ve karma teknikler olarak literatüre girmiştir (Bilgin ve Çamurcu, 2008). İkon tabanlı teknikler çok boyutlu bilgi dokümanlarını ikon şeklinde sembolleştirir. Bu ikonların görselliği sembolize ettiği bilginin içeriğinde ele aldığı konuların muhtevasına göre değişir. Bu tekniğin ilk çalışmaları Chernoff yüzleri tekniğidir. $\mathrm{Bu}$ teknikte her veri nesnesi için ayrı ayrı insan yüzü çizilir. Nesneye ait ilk iki boyut yüz resminin 2 boyutlu düzlemdeki konumu belirtir. Diğer boyutların aldığı değerler ile orantılı olarak insan yüzünün burun, ağı, kulak, göz ve yüz şekli değiştirilir (Gürler vd., 2018)

$\mathrm{Bu}$ çalışmada 20 devlet ve 2 özel olmak üzere 22 üniversitenin istatistik bölümü mezunlarının KPSS sınavına katılıp İstatistik, Ekonometri, Genel Kültür, Genel Yetenek, İktisat, İşletme, Kamu Yönetimi, Maliye, Muhasebe, Çalışma Ekonomisi ve Hukuk 
olmak üzere 11 farklı alanda almış oldukları ortalama başarı puanlarına göre üniversiteleri karşılaştırmak için veri görselleştirme yöntemlerinden Chernoff'un yüzleri grafiği yöntemi kullanılmıştır.

\subsubsection{Chernoff'un Yüzleri}

Chernoff yüzleri çok değişkenli ve karmaşık verileri görsel olarak görüntüleyip yorumlamak için insan yüz karikatürü çizimlerdir. Burada insan yüzündeki ağız, burun, kulak, göz, çene, kaş gibi özellikleri ve bunlarda meydana gelen farkl1liklar kullanılır (Spinelli ve Zhou, 2004).

Chernoff yüzlerinin amac1, bir veri setindeki sayılara dayanarak, kulaklar, saçlar, gözler ve burun gibi insan yüzünün kısımlarını konumlandirarak bir kerede birden fazla değişken göstermektir. Gerçek hayatta İnsanların yüzleri kolayca okunabildiği düşünüldüğü bu yüzler verileri temsil ettiklerinde küçük farklılıklar belirlenebilir (https://flowingdata.com/2010/08/31/how-tovisualize-data-with-cartoonish-faces/).

$\mathrm{Bu}$ grafik yönteminde her bir veri nesnesi için bir yüz çizilir ve yüzlerdeki ağız, burun, kulak, göz, çene, kaş gibi organlara veriler atanır. Atanan verilere göre yüzdeki organların boyutları oranlanır. Böylece farklı yüz tipleri ortaya çıkar (Kulaç, 2019).

Chernoff yüzleri yöntemi oldukça kullanışı bir veri görselleştirme yöntemi olmasına rağmen insan yüzündeki bazı organların diğerlerine göre daha dikkat çekmesi bu yöntemin dezavantajıdır. Örneğin gözler kulaklara göre daha çabuk ve dikkatli algılandığından karşılaştırmalar yapılırken daha dikkatli davranmak gerekir (Bilgin ve Çamurcu, 2008; Kulaç, 2019).
İkon tabanlı teknikler birçok boyutlu veri nesnesini bir ikon şeklinde sembolize ederler. İkonun her bir görsel özelliği verinin içerdiği değerlere göre değişir. $\mathrm{Bu}$ türün ilk örneklerinden biri Chernoff yüzleri tekniğidir Her veri nesnesi için bir insan yüzü çizilir. Nesneye ait ilk iki boyut yüz resminin 2 boyutlu düzlemdeki konumu belirtir. Diğer boyutların aldığı değerler ile orantılı olarak insan yüzünün burun, ağı, kulak, göz ve yüz şekli değiştirilir (Bilgin ve Çamurcu, 2008).

Chernoff yüzleri çizmek için her bir veri grubu için bir renk belirlenir. Veri grubu az olduğunda birbirinden kolay bir şekilde ayırt edilebilen renkler tercih edilir. Veri grubu fazla olduğunda ana renklerin farklı tonları da kullanılır. $\mathrm{Bu}$ çalışmada veri grubu (22 üniversite) fazla olduğundan ana renkler ve bu ana renklerin farklı tonları da kullanılmıştır.

$\mathrm{Bu}$ çalışmada Chernoff yüzleri çizmek için materyal kısmında verilmiş olan veri seti için SYSTAT programı kullanılmıştır.İlgili programda verilerin yüz ikonlarına atanma sıralaması aşağıdaki gibidir:

1. A ̆ğı eğriliği: Ağız kenarlarının yukarı doğru, düz, aşağı doğru oluşunu ifade eder. İSTATISTTIK

2. Kaş açısı: Kaşların yukarı doğru çatık oluşu, normal oluşu, aşağı doğru çatık oluşunu ifade eder. EKONOMETRİ

3. Burun genişliği: Burunun geniş bir üçgen şeklinden dar bir üçgen şekline doğru şekil almasını ifade eder. GENEL KÜLTÜR

4. Burun uzunluğu: Burunun dik uzunluğunun uzundan kısaya doğru şekil almasını ifade eder. GENEL YETENEK 
5. A $\breve{g} 1 z$ uzunluğu: Ağız boyunun uzundan kısaya doğru şekil almasını ifade eder. İKTISAT

6. Ağzın buruna olan yakınlığı: Ağız ile burun arasındaki mesafenin uzak mesafeden yakın mesafeye doğru şekil almasını ifade eder. İŞLETME

7. Gözlerin ayrıklığı: Gözlerin birbirine uzak oluşundan yakın oluşuna doğru şekil almasını ifade eder. KAMU YÖNETIMİ

8. Gözlerin yüzdeki yüksekliği: Gözlerin, suratın üst tarafından alt tarafına doğru konumlanmasını ifade eder. MALIYYE

9. Gözlerin eğikliğgi: Gözlerin yukarı ve aşağı doğru çekik olmasını ifade eder. MUHASEBE

10. Gözlerin eksantrikliği: ÇALIŞMA EKONOMISİ

11. Gözlerin yatay uzunluğu: Göz uzunluğun uzun veya kısa olarak şekillenmesini ifade eder. HUKUK

\section{VERILERIN BULGULAR}

ANALIZİ VE

Chernoff grafiği çizmek için SYSTAT programı kullanılmıştır. $\mathrm{Bu}$ programda verilerin yüz ikonlarına atanma sıralaması aşağıdaki gibidir:

1. Ağız eğriliği: Ağız kenarlarının yukarı doğru, düz, aşağı doğru oluşunu ifade eder. İSTATISTIIK

2. Kaş açısı: Kaşların yukarı doğru çatık oluşu, normal oluşu, aşağı doğru çatık oluşunu ifade eder. EKONOMETRİ
3. Burun genişliği: Burunun geniş bir üçgen şeklinden dar bir üçgen şekline doğru şekil almasını ifade eder. GENEL KÜLTÜR

4. Burun uzunluğu: Burunun dik uzunluğunun uzundan kısaya doğru şekil almasını ifade eder. GENEL YETENEK

5. Ağı uzunluğu: Ağız boyunun uzundan kısaya doğru şekil almasını ifade eder. İKTİSAT

6. Ağzın buruna olan yakınlığı: Ağız ile burun arasındaki mesafenin uzak mesafeden yakın mesafeye doğru şekil almasını ifade eder. İșLETME

7. Gözlerin ayrıklığı: Gözlerin birbirine uzak oluşundan yakın oluşuna doğru şekil almasını ifade eder. KAMU YÖNETIMII

8. Gözlerin yüzdeki yüksekliği: Gözlerin, suratın üst tarafından alt tarafina doğru konumlanmasını ifade eder. MALIYE

9. Gözlerin eğikliği: Gözlerin yukarı ve aşağı doğru çekik olmasını ifade eder. MUHASEBE

10. Gözlerin eksantrikliği: ÇALIŞMA EKONOMISI

11. Gözlerin yatay uzunluğu: Göz uzunluğun uzun veya kısa olarak şekillenmesini ifade eder. HUKUK

\section{1. BULGULAR}

Çalışmada kullanılan veri seti için SYSTAT programı kullanılarak çizilen Chernoff yüzleri ekran görüntüsü Şekil-1'de verilmiştir. 


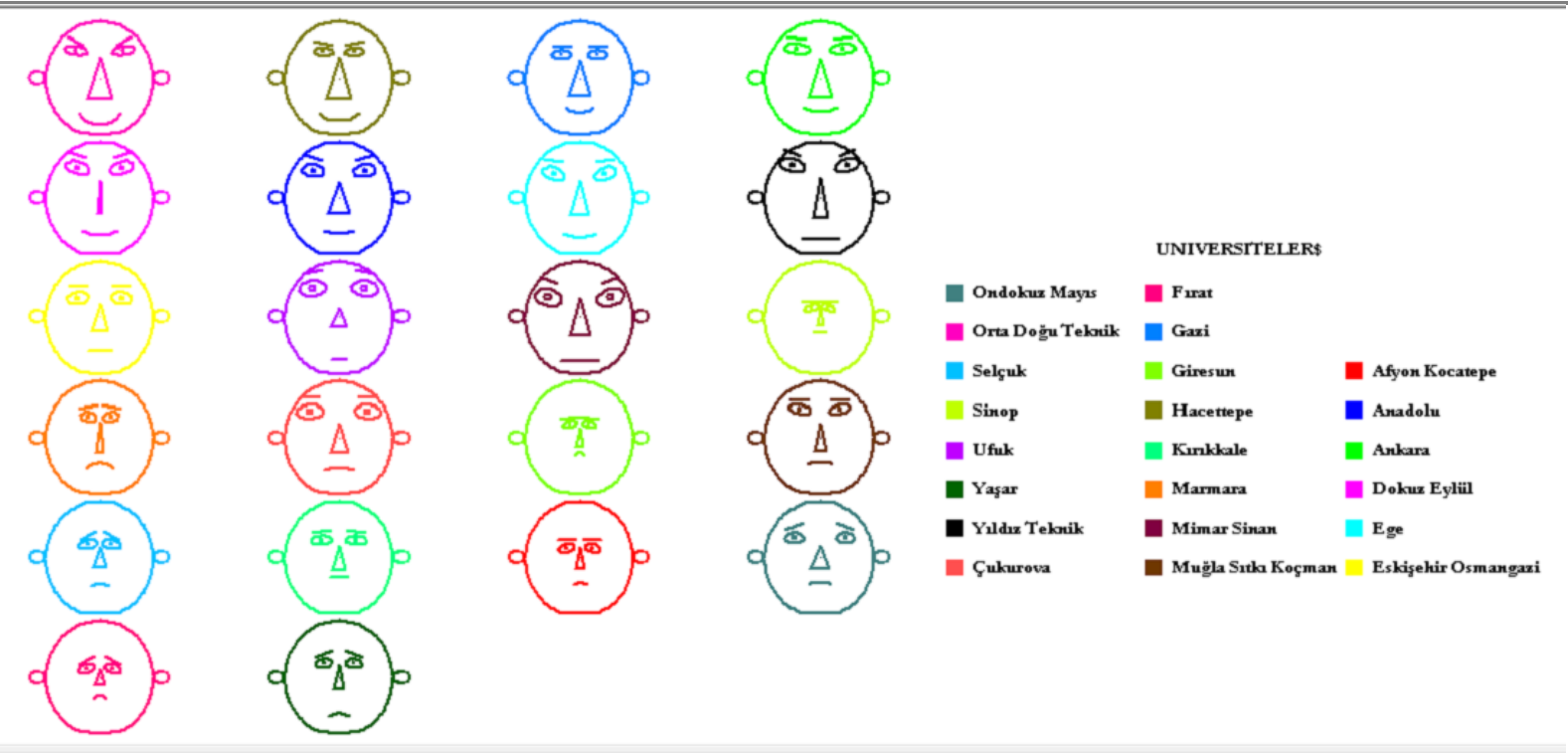

Şekil 1 incelendiğinde Üniversitelerin İstatistik bölümlerinin söz konusu alanlara göre KPSS başarı puanlarına göre karşılaştırmaları aşağıdaki gibi yapılabilir:

- KPSS İstatistik başarı ortalaması en yüksek olan ilk üç üniversite sırasıyla; Orta Doğu Teknik, Hacettepe, Gazi Üniversitesidir. Ağız kenarları yukarı doğru en kıvrık olanlar sırasıyla bu üç üniversitedir. KPSS istatistik başarı ortalaması en düşük olan üniversite, ağ1Z kenarları en aşağıda olan Firat Üniversitesidir.

- KPSS Ekonometri başarı ortalaması en yüksek olan ilk üç üniversite sırasıyla; Orta Doğu Teknik, Yıldız Teknik ve Mimar Sinan Güzel Sanatlar Üniversitesidir. En çatık kaşlar sırasıyla bu üç üniversiteye aittir. Kaşlarının dış kenarları en aşağıda olan üniversite ise ekonometride KPSS başarı ortalaması en düşük olan Fırat Üniversitesidir.

- KPSS Genel Kültür başarı ortalaması en yüksek olan üniversiteler sirasiyla en geniş buruna sahip olan Orta Doğu Teknik, Hacettepe, Ankara Üniversitesidir. En dar burun sahibi olan Dokuz Eylül Üniversitesi KPSS genel kültür başarı ortalaması en düşük olan üniversitedir.

- KPSS Genel Yetenek en yüksek başarı ortalaması sirasiyla en uzun buruna sahip olan Orta Doğu Teknik, Hacettepe, Yıldız Teknik Üniversitesi iken; en düşük başarı ortalamasına sahip olan en kısa burunlu olan Sinop Üniversitesidir.

- KPSS İktisat en yüksek başarı ortalaması sırasıyla en geniş ağza sahip olan Orta Doğu Teknik, Ufuk, Yıldız Teknik Üniversitesidir. En dar ağza sahip olan 
Giresun Üniversitesi' nin KPSS iktisat başarı ortalaması en düşüktür.

- KPSS İşletme en yüksek başarı ortalaması, sırasıyla ağız ile burun arasındaki en geniş mesafeye sahip olan Orta Doğu Teknik, Ufuk, Mimar Sinan Güzel Sanatlar Üniversitesidir. Ağız ile burun arasındaki en dar mesafeye sahip olan Giresun Üniversitesi ise KPSS işletme başarı ortalaması en düşük olan üniversitedir.

- KPSS Kamu Yönetimi en yüksek başarı ortalaması sırasıyla en ayrık gözlere sahip olan Mimar Sinan Güzel Sanatlar, Çukurova, Yıldız Teknik Üniversitesidir. En düşük KPSS kamu maliyesi başarı ortalaması ise en bitişik gözlere sahip olan Sinop Üniversitesidir.

- KPSS Maliye başarı ortalaması en yüksek olan üniversiteler sırasıyla, gözleri yüzde en yukarıda olan Yıldız Teknik, Ufuk, Dokuz Eylül Üniversitesidir. Gözleri en aşağıda olan Afyon Üniversitesi'nin KPSS maliye başarı ortalaması düşüktür.

- KPSS Muhasebe başarı ortalaması en yüksek olan üniversiteler sırasıyla, yukarı doğru en çekik gözlere sahip olan Ege, Dokuz Eylül, Mimar Sinan Güzel Sanatlar Üniversitesidir. Așağı doğru en çekik gözlere sahip olan Afyon Üniversitesinin KPSS Muhasebe başarı ortalaması oldukça düşüktür.

- KPSS Çalışma Ekonomisi başarı ortalaması en yüksek olan üniversiteler sırasıyla en farklı göz çeperine sahip olan Mimar Sinan Güzel Sanatlar, Marmara ve Ufuk Üniversitesidir. Çalışma Ekonomisi başarı ortalaması en düșük olan üniversite ise Orta Doğu Teknik Üniversitesidir.

- KPSS Hukuk başarı ortalaması en yüksek olan üniversiteler sirasıyla, en uzun göz yapısına sahip olan Mimar Sinan Güzel Sanatlar, Ufuk ve Ankara Üniversitesidir. En düşük KPSS hukuk başarı ortalaması ise en kısa göz yapısına sahip Giresun Üniversitesidir.

\section{Sonuç}

Verilerde boyut sayısı arttıkça algılama ve yorumlama güçleşmektedir. Bu durumda veri görselleştirilerek algılama ve anlama kolaylaşmakta ve süresi kısalmaktadır. Ayrıca veriler ve değişkenler arasındaki gizli ilişkiler, görselleştirme tekniği ile açığa çıkabilmektedir. Birçok veri görselleştirme yöntemi vardır. Bunlardan biri Chernoff yüzleri grafiğidir. $\mathrm{Bu}$ çalışmada Chernoff yüzleri yöntemi kullanılarak üniversitelerin istatistik bölümlerinin kpss başarı puanları bakımından karşılaştırılması yapılmıştır. Çalışma neticesinde hangi üniversitelerin hangi alanlarda daha başarılı (sırasıyla en başarılı 3 üniversite) ve başarısız (en başarısız 1 üniversite) olduğu aşağıdaki Tablo-2'de özetlenmiştir. 
Tablo 2. En Başarılı ve En Başarısız Üniversiteler

\begin{tabular}{|c|c|c|c|c|c|c|c|c|c|c|c|}
\hline Üniversiteler & 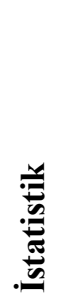 & 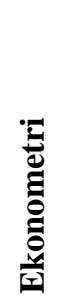 & 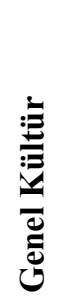 & 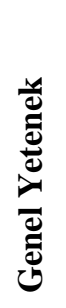 & ב气 & 窇 & 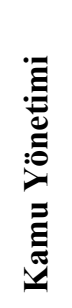 & 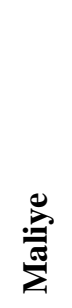 & 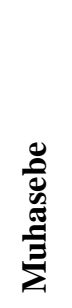 & 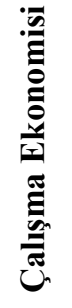 & $\frac{y}{E}$ \\
\hline Orta Doğu Teknik Üniv. & 1 & 1 & 1 & 1 & 1 & 1 & & & & 22 & \\
\hline Hacettepe Üniv. & 2 & & 2 & 2 & & & & & & & \\
\hline Gazi Üniv. & 3 & & & & & & & & & & \\
\hline Ankara Üniv. & & & 3 & & & & & & & & 3 \\
\hline Dokuz Eylül Üniv. & & & 22 & & & & & 3 & 2 & & \\
\hline Ege Üniv. & & & & & & & & & 1 & & \\
\hline Yıldız Teknik Üniv. & & 2 & & 3 & 3 & & 3 & 1 & & & \\
\hline Ufuk Üniversitesi & & & & & 2 & 2 & & 2 & & 3 & 2 \\
\hline Mimar Sinan Güzel Üniv. & & 3 & & & & 3 & 1 & & 3 & 1 & 1 \\
\hline Sinop Üniv. & & & & 22 & & & 22 & & & & \\
\hline Marmara Üniv. & & & & & & & & & & 2 & \\
\hline Çukurova Üniv. & & & & & & & 2 & & & & \\
\hline Giresun Üniv. & & & & & 22 & 22 & & & & & 22 \\
\hline Afyon Kocatepe Üniv. & & & & & & & & 22 & 22 & & \\
\hline Fırat Üniv. & 22 & 22 & & & & & & & & & \\
\hline
\end{tabular}

Tablo-2 başarı bakımından incelendiğinde İstatistik, Ekonometri, Genel Kültür, Genel Yetenek, İktisat ve İşletme alanlarında en başarılı üniversitenin Orta Doğu Teknik Üniversitesi olduğu; Kamu Yönetimi, Çalışma Ekonomisi ve Hukuk alanlarında en başarılı üniversitenin Mimar Sinan Güzel Sanatlar Üniversitesi olduğu; Maliye alanında en başarılı üniversitenin Yıldız Teknik Üniversitesi olduğu; Muhasebe alanında en başarılı üniversitenin Ege Üniversitesi olduğu görülmektedir. İstatistik, Genel Kültür ve Genel Yetenek alanlarında ikinci sırada en başarılı üniversitenin Hacettepe Üniversitesi olduğu; Ekonometri alanında ikinci sırada en başarılı üniversitenin Yıldız Teknik Üniversitesi olduğu; İktisat, İşletme, Maliye ve Hukuk alanlarında ikinci sırada en başarılı üniversitenin Ufuk Üniversitesi olduğu; Çalışma Ekonomisi alanında ikinci sırada en başarılı üniversitenin Marmara Üniversitesi olduğu; Kamu Yönetimi alanında ikinci sırada en başarılı üniversitenin Çukurova Üniversitesi olduğu görülmektedir. İstatistik alanında üçüncü sırada en başarılı üniversitenin Gazi Üniversitesi olduğu; Genel Kültür ve Hukuk alanlarında üçüncü sırada en başarılı üniversitenin Ankara Üniversitesi olduğu; Maliye alanında üçüncü sırada en başarılı üniversitenin Dokuz Eylül Üniversitesi olduğu; Genel Yetenek, İktisat 
ve Kamu Yönetimi alanlarında üçüncü sırada en başarılı üniversitenin Yıldız Teknik Üniversitesi olduğu; Çalışma Ekonomisi alanında üçüncü sırada en başarılı üniversitenin Ufuk Üniversitesi olduğu; Ekonometri, İşletme ve Muhasebe alanlarında üçüncü sırada en başarılı üniversitenin Mimar Sinan Güzel Sanatlar Üniversitesi olduğu görülmektedir.

Tablo-2 başarısızlık bakımından incelendiğinde İstatistik ve Ekonometri alanında en başarısız üniversitenin Fırat Üniversitesi olduğu; Genel Kültür alanında en başarısız üniversitenin Dokuz Eylül Üniversitesi olduğu; Genel Yetenek ve Kamu Yönetimi alanında en başarısız üniversitenin Sinop Üniversitesi olduğu; İktisat, İşletme ve Hukuk alanında en başarısız üniversitenin Sinop Üniversitesi olduğu; Maliye ve Muhasebe alanında en başarısız üniversitenin Afyon Kocatepe Üniversitesi olduğu; Çalışma Ekonomisi alanında en başarısız üniversitenin Orta Doğu Teknik Üniversitesi olduğu görülmektedir.

\section{Kaynaklar}

Bezerra, R.F., Jalloh, S. ve Stevenson, J. 1998. "Formulating Hypotheses Graphically in SocialResearch", Quality\&Quantity, 32 (1), 327-353.

Bilgin, T.T. ve Çamurcu, A.Y. 2008. "Çok Boyutlu Veri Görselleştirme Teknikleri”, Akademik Bilişim 2008 Konferansı, Çanakkale Onsekiz Mart Üniversitesi, Çanakkale, 2008.

Çelik, S., Akdamar, E. 2018. "Büyük Veri ve Veri Görselleştirme”, Akademik Bakış Dergisi, Uluslararası Hakemli Sosyal Bilimler E-Dergisi, 65, 253-264.
Fienberg, S.E. 1979."GraphicalMethods in Statistics", The American Statistician, 33(4), 165-178.

Gürler, A., Yilmaz, A. S. ve Tekerek, M. 2018. "Veri Görselleştirme ve İnfografikler", KSÜ Mühendislik Bilimleri Dergisi, 21(2), 131-148.

Keim, D.A. 1997. "Visual Database Explorati on Techniques", Proc. Tutorial KDD '97 Intl. Conf. Knowledge Discoveryand Data Mining, California, USA.

Kulaç, E. 2019. "Çok Değişkenli Verilerin Görsel Sunumu”, Basılmamış Yüksek Lisans Tezi, Sivas Cumhuriyet Üniversitesi Sosyal Bilimler Enstitüsü, Sivas.

Wainer, H. 1992. "UnderstandingGraphs and Tables", Educational Researcher, 21(1),1423.

Y1ldı, R. ve Yıldırım, E. 2012. "Tez Yazma, Makale Hazırlama ve Yayınlama Kilavuzu”, Detay Yayınc1lık, Ankara.

www.verigazeteciligi.com > verigorsellestirme-nedir, Son Erişim Tarihi: 20/10/2019

www.halksagligi.hacettepe.edu.tr sunumlar_ve_seminerler > epidemiyoloji, Son Erişim Tarihi: 20/10/2019

https://flowingdata.com/2010/08/31/how-tovisualize-data-with-cartoonish-faces/, Son Erişim Tarihi: 01/10/2019 